\title{
Esterification of Microwave Induced Pyrolytic Oil from Sago Bark Waste
}

\author{
Rafeah Wahi $^{1} \cdot$ Syamila Aimi Yahaya ${ }^{1} \cdot$ Su Shiung Lam ${ }^{2} \cdot$ Sharifah Mona Abdul Aziz ${ }^{3} \cdot$ Zainab Ngaini $^{1}$
}

Received: 22 June 2018 / Accepted: 11 March 2019

(c) Springer Nature B.V. 2019

\begin{abstract}
In this study, microwave induced pyrolytic oil from sago bark (SB) was subjected to esterification to improve its properties. Improvement on properties of the pyrolytic oil was performed via esterification with ethanol and the presence of sulfuric acid as a catalyst. The optimum esterification condition was studied using general factorial design. The esterified oil (EO) showed improved properties with $\mathrm{pH}$ (4-6), reduced moisture content (2.95-3.45\%), density $\left(0.9-1.1 \mathrm{~g} \mathrm{~cm}^{-3}\right)$, and acid value (39.3-123.4 mg KOH $\mathrm{g}^{-1}$ ), and maintained the $\mathrm{CV}\left(20.2-21.6 \mathrm{MJ} \mathrm{kg}^{-1}\right)$. GC-MS analysis showed that EO was sulphur free, and low in carboxylic acid and oxygenated compounds. The optimal esterification condition with optimum quality of EO was at $65^{\circ} \mathrm{C}$ temperature, $60 \mathrm{~min}$ reaction time and 1:1 ethanol to oil volume ratio. Results indicated that the EO can be potentially used in robust combustion engines upon properties refinement.
\end{abstract}

Keywords Esterification $\cdot$ Sago bark $\cdot$ Microwave pyrolysis $\cdot$ Esterified oil

\section{Statement of Novelty}

A number of studies have shown that pyrolytic oil upgrading via esterification is well established. However, no comprehensive study was dedicated to upgrading of sago pyrolytic oil via esterification process.

\section{Introduction}

Microwave pyrolysis is a promising alternative to resolve the challenges in terms of improving the yield and quality of the resultant liquid biofuels and increase energy efficiency of the whole biomass to liquid fuel product conversion process

Syamila Aimi Yahaya

syamilaaimi_90@hotmail.com

1 Faculty of Resource Science and Technology, Universiti Malaysia Sarawak, 94300 Kota Samarahan, Sarawak, Malaysia

2 Pyrolysis Technology Research Group, Eastern Corridor Renewable Energy Group, School of Ocean Engineering, Universiti Malaysia Terengganu, 21030 Kuala Nerus, Terengganu, Malaysia

3 Centre for Pre-University Studies, Universiti Malaysia Sarawak, 94300 Kota Samarahan, Sarawak, Malaysia
[1]. However, any pyrolytic oil, more than often has several drawbacks of pyrolytic oil are the low heating value, high viscosity, high corrosiveness and poor stability [2]. The aforementioned problems limit the potential of the pyrolytic oil as fuel material.

Pyrolytic oil is very complex in composition and contains large amount of oxygenated compounds such as aldehydes and ketones [3]. Direct usage of pyrolytic oil for internal combustion is not practical because of the oxygenated compounds contents and high acidity and corrosiveness of the pyrolytic oil. Thus, it is necessary to improve the pyrolytic oil properties by reducing water, oxygenated and acidic content before it can be used as fuel [4].

A number of chemical modification techniques has been studied for upgrading the pyrolytic oil such as hydrodeoxygenation [5], supercritical fluid treatment [6] and esterification [7]. These processes are able to reduce acidity and increase calorific value (CV). In esterification process, the carboxyl groups in the pyrolytic oil are converted to the corresponding esters to improve the quality of pyrolytic oil in terms of odour, corrosiveness and stability [8]. As a result of its simplicity, low temperature and pressure, low cost of some alcohols like methanol, esterification seems to be one of the promising techniques to upgrade the pyrolytic oil [9].

In esterification reaction, carboxylic acids react with alcohol at atmospheric pressure in the presence of an acid 